Psicologia Escolar

e Educacional
ARTIGO

DOI: http://dx.doi.org/10.1590/2175-35392020217022

Elocid - e217022

\title{
CONCEPÇÕES DE PROFESSORES SOBRE A POLÍTICA DE EDUCAÇÃO INCLUSIVA: UM ESTUDO DE CASO
}

\author{
Marcelo Domingues Roman ${ }^{1} \mathbb{D}$; Elaine Soares da Silva Molero ${ }^{1} \mathbb{D}$; Carla Cilene Baptista da Silva ${ }^{1} \mathbb{D}$
}

\section{RESUMO}

Este estudo investigou como professores entendem a educação inclusiva, buscando conhecer suas dificuldades e necessidades para a efetivação desta política. Para isso, realizou e analisou entrevistas com oito professoras de salas regulares do ensino fundamental, de três escolas públicas de um município do litoral paulista. As concepções das professoras acerca de inclusão envolveram desde um processo de ensino voltado a alunos com necessidades educacionais especiais com dificuldades de acompanhar os conteúdos regulares até a mera socialização ou simples concretização de um direito. Entre as dificuldades apontadas estão a extensa jornada de trabalho, o grande número de alunos por sala e a falta de apoio especializado. A análise desses apontamentos remete às reformas neoliberais do Estado, sobretudo no que tange às suas funções fiscalizadora e de contenção de gastos, o que impacta a execução de políticas sociais. Concluiu-se que a efetivação desta política pressupõe reformas urgentes no sistema geral de ensino.

Palavras-chave: Professores; educação inclusiva; saúde.

\section{Teachers' conceptions of inclusive education policy: a case study}

\begin{abstract}
This study investigated how teachers understand inclusive education, seeking to know its difficulties and needs for the implementation of this policy. To this end, it conducted and analyzed interviews with eight teachers from regular elementary schools, from three public schools in a city on the coast of São Paulo. The teachers' conceptions about inclusion ranged from a teaching process aimed at students with special educational needs with difficulties in following the regular contents to the mere socialization or simple realization of a right. Among the difficulties pointed out are the long working hours, the large number of students per class and the lack of specialized support. The analysis of these notes refers to the neoliberal reforms of the State, especially with regard to its supervisory functions and cost containment, which affects the implementation of social policies. It was concluded that the implementation of this policy presupposes urgent reforms in the general education system.
\end{abstract}

Keywords: Teachers; inclusive education; health.

\section{Concepciones de profesores sobre la política de educación inclusiva: un estudio de caso}

\section{RESUMEN}

En este estudio se investigó cómo profesores entienden la educación inclusiva, buscando conocer sus dificultades y necesidades para la efectividad de esta política. Para eso, se realizó y analizó entrevistas a ocho profesoras de clases regulares de lo enseñanza básica, de tres escuelas públicas de un municipio del litoral paulista. Las concepciones de las profesoras acerca de inclusión abarcan desde un proceso de enseñanza volcada a alumnos con necesidades educacionales especiales con dificultades de acompañar los contenidos regulares hasta la simple socialización o simple concretización de un derecho. Entre las dificultades apuntadas están la extensa jornada de trabajo, el gran número de alumnos por clase y la falta de apoyo especializado. El análisis de esos apuntes remete a las reformas neoliberales del Estado, sobre todo en lo que se refiere a sus funciones fiscalizadora y de contención de gastos, lo que impacta la ejecución de políticas sociales. Se concluye que la efectividad de esta política presupone reformas urgentes en el sistema general de enseñanza.

Palabras clave: Profesores; educación inclusiva; salud.

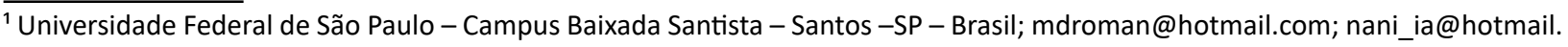
com; carlaci@gmail.com
} 


\section{INTRODUÇÃO}

As discussões acerca da inclusão escolar envolvem inúmeras outras, não se tratando de um processo isolado, mas com implicações amplas nos campos político, cultural, econômico e social. Vivemos em uma sociedade formalmente democrática, que contém em seus dispositivos jurídicos a defesa da pluralidade, do convívio social e da interlocução na diversidade. 0 direito de participar dos espaços e processos comuns de ensino e aprendizagem realizados pela escola está previsto em legislação e as políticas educacionais devem ser compatíveis com esses pressupostos (Brasil, 2008).

No Brasil, um dos importantes documentos balizadores nessa área é a Política Nacional de Educação Especial na Perspectiva da Educação Inclusiva (Brasil, 2008). Tal documento tece críticas à escola como instituição que historicamente reproduz a desigualdade e a discriminação presentes no funcionamento básico de nossa sociedade. O documento aponta que o processo de democratização da educação, enquanto anseio das classes trabalhadoras e simultaneamente pautado pelos interesses das classes dirigentes, evidencia, no interior da escola, o paradoxo entre inclusão e exclusão a partir do qual nossa sociedade se edifica: ninguém está do lado de fora da sociedade, mas esta funciona excluindo enormes fatias da população do acesso a condições mínimas de vida digna. Da mesma forma, a universalização do acesso à educação formal não assegura acesso ao conhecimento escolar e consequente desenvolvimento para todos, pois a exclusão se reproduz no interior das salas de aula, sobretudo para indivíduos e grupos considerados divergentes dos padrões homogeneizadores da escola. O paradigma da educação inclusiva busca combater tal exclusão, responsabilizando o sistema escolar pelas adaptações físicas e atitudinais para que todos possam aprender, inclusive alunos com deficiência.

Esse paradigma está presente em documentos internacionais como a Declaração Mundial de Educação para Todos (UNESCO, 1990) e a Declaração de Salamanca (UNESCO, 1994), que norteiam as políticas de educação inclusiva em todo o mundo. Contudo, há um longo caminho entre a formulação de políticas públicas e sua concretização. Nesse sentido, vários fatores concorrem para a materialização da educação inclusiva: a estrutura institucional do sistema escolar, as marcas deixadas pelas políticas anteriores, as concepções acerca do ato de educar e da população a que se dirige, os investimentos destinados ao funcionamento da escola, as políticas de formação de professores, entre outros. Todavia, esses fatores convergem para o que fazem e pensam professores nas escolas. São eles que concretizam, nas salas de aula, as políticas educacionais. É a partir dessa constatação que este trabalho se dispõe a analisar as concepções de professores sobre a atual política de educação inclusiva, buscando compreender sua real efetivação.

As análises aqui realizadas também partem de determinadas concepções de educação e sociedade, de Estado e de políticas públicas. Em síntese, compreende-se educação a partir de sua relação dialética com a sociedade. Educação e sociedade se constituem mutuamente, porém, sendo parte do todo social, a educação preponderantemente reproduz o funcionamento social. Todavia, a educação também ocupa um papel contraditório, o de transformação. Isso porque a própria sociedade em que vivemos é marcada pela contradição entre as classes que a constituem, reservando à imensa maioria exploração e precariedade das condições de vida, a fim de que minorias possam acumular riquezas e governar em benefício próprio. O Estado é o aparato a partir do qual esse governo é exercido, não sem intensas disputas. As contradições que atravessam a sociedade capitalista também atravessam o Estado e as políticas a partir das quais ele busca organizar os diversos setores sociais. Assim, a política de educação inclusiva manifesta, em seus ideais e práticas, os paradoxos de seu tempo histórico, marcado pelo ideário neoliberal e pela luta pela manutenção dos direitos sociais.

\section{Concepções acerca da educação inclusiva}

O tema da educação inclusiva é frequentemente pautado por dificuldades e indefinições que se apresentam no cotidiano escolar, em contraposição à aparente solidez e clareza expostas nas diretrizes e legislações. Dessa forma, recorrentes considerações são feitas por professores tendo em vista suas vivências com a educação inclusiva, reiterando a importância da formação do professor de classe regular para o atendimento educacional de todas as crianças, com ou sem deficiências.

A necessidade de formação dos agentes educacionais está preconizada na Declaração de Salamanca (UNESCO, 1994) e na atual Política Nacional de Educação Especial na Perspectiva da Educação Inclusiva, que orienta os sistemas de ensino a garantir “... formação de professores para o atendimento educacional especializado e demais profissionais da educação para a inclusão escolar? (Brasil, 2008, p. 10). Do mesmo modo, o Programa Educação Inclusiva, implementado pelo MEC em 2005, promoveu um amplo processo de formação de gestores e educadores nos municípios brasileiros para a garantia do direito de acesso de todos à escolarização e ao atendimento educacional especializado (Brasil, 2005).

Entretanto, à época, Sant?Ana (2005) já nos mostra questões frequentemente apontadas pelos educadores referentes à falta de formação e experiência prévias, bem como à ausência de estratégias específicas junto a alunos com deficiências, sendo que o sucesso de sua intervenção depende da implementação de amplas mudanças nas práticas pedagógicas, quais sejam: a 
adoção de novos conceitos e estratégias, a adaptação ou (re)construção de currículos, o uso de novas técnicas e recursos específicos para essa clientela e o estabelecimento de novas formas de avaliação.

Sant?Ana (2005) ainda ressalta que a formação docente não deve restringir-se à participação em cursos eventuais, mas também precisa abranger programas de capacitação, supervisão e avaliação realizados de forma integrada e permanente. Além disso, o professor precisa ser auxiliado no exercício da reflexão sobre sua prática, para que compreenda suas crenças em relação ao processo e se torne um pesquisador de sua ação, buscando aprimorá-la. Como ressalta Pletsch (2009), é necessária uma formação que possibilite ao professor mobilizar seus conhecimentos, articulando-os com suas competências mediante ação e reflexão teórico-prática. Nesse sentido, Anjos (2015) desenvolve uma ?pesquisaformação[?, por meio da qual estabelece uma relação entre universidade e professores, atribuindo a esses um protagonismo no processo contínuo de formação. Esse protagonismo parte da reflexão, por parte dos professores, acerca de suas próprias histórias enquanto educadores, do entrelaçamento entre essas histórias e a história das políticas educacionais e, nesse processo, da formação de suas identidades profissionais, sempre em trânsito. Dessa forma, seria possível fazer frente às frequentes avaliações negativas de professores sobre os programas de formação, tidos como insuficientes e inadequados à realidade escolar (Matos \& Mendes, 2015). Todavia, é preciso considerar ainda que o sucesso do processo de ensino-aprendizagem a todos na escola depende de uma atitude positiva não apenas do professor, mas de todos os agentes envolvidos nesse processo.

A inclusão, segundo Jesus (2004), avança na compreensão de que a escola deve funcionar como espaço social e efetuar mudanças para incluir todos os seus alunos, inclusive aqueles que demandam maior apoio no processo educacional, assumindo uma postura de construtora de uma equidade capaz de colaborar para incluir na tessitura social aqueles que vêm sendo sistematicamente excluídos, de forma que a diversidade humana possa fazer-se presente como valor universal. Em outras palavras, de acordo com Figueiredo (2002), a inclusão significa um avanço educacional com importantes repercussões políticas e sociais, de forma que não se trata de adequar o indivíduo ao funcionamento institucional, mas de transformar a realidade das práticas educacionais.

Alguns autores, como Sant?Ana (2005), indicam aparentes alterações nas concepções dos educadores, que estariam mais relacionadas às ideias de inclusão do que de integração. Isso estaria relacionado às recentes discussões sobre inclusão nas diversas esferas sociais, inclusive com destaque na mídia, assim como por influência de leituras e formações que facilitam a compreensão e a distinção dos significados.

Outros autores, como Anjos, Andrade e Pereira (2009), identificam discursos ambíguos em relação ao tema, em que a inclusão aparece tanto como processo quanto como produto. No primeiro caso, representa uma ação humana caracterizada por tentativas e erros, em que o professor pode se colocar de forma mais ou menos implicada. No caso de ser concebida como produto, toma a forma de algo idealizado, que ocorre ou não e depende sobretudo da compreensão dos envolvidos, reservando menor espaço para a ação do professor. Essa ambiguidade pode ser associada a um período de transição, em que uma crise em direção a novas experiências educacionais motivaria sentimentos de despreparo, improviso, inventividade e impotência, em face de um aparato institucional que aparece como externo à ação dos professores.

A partir dessas considerações, o presente estudo visa investigar como professores entendem a educação inclusiva, buscando, também, conhecer as dificuldades e as necessidades apontadas pelos profissionais no processo de inclusão de crianças com deficiência no ensino público regular.

\section{MÉTODO}

Participaram desse estudo oito professoras de salas regulares de ensino fundamental, atuantes na rede municipal de uma cidade do litoral paulista, sendo que essas estavam, no momento da pesquisa, ministrando aulas para crianças com deficiências em suas classes. As professoras eram de três unidades educacionais de diferentes regiões da cidade e com diversos perfis socioeconômicos. Todas eram do sexo feminino, sendo que o menor e o maior tempo de trabalho das mesmas eram de 07 e 30 anos, respectivamente, tanto na rede estadual como na municipal. No que diz respeito à atuação com crianças com deficiências, o relato de menor tempo de experiência é de 01 ano e o maior de 30 anos.

As entrevistas foram realizadas nas próprias escolas e em horários escolhidos pelas professoras. As participantes assinaram Termos de Consentimento Livre e Esclarecido, aprovados pelo Comitê de Ética em Pesquisa da Universidade Federal de São Paulo sob o número 1628/07.

Foi utilizado um roteiro para entrevista semiestruturada, além de equipamento de gravação para registro dos dados e posterior transcrição e análise do material. $O$ roteiro pretendeu focar as seguintes dimensões: conceitos, ideias e opiniões que as profissionais manifestavam acerca da Educação Inclusiva enquanto política pública (estruturação institucional para promoção da inclusão nos níveis nacional e municipal) e enquanto prática (experiência prévia, trabalho cotidiano, uso de tecnologias assistivas, salas de recursos multifuncionais, participação da família e colaboração de instituições 
especializadas).

Após a transcrição dos relatos, foi feita uma leitura ampla do material obtido. Em seguida, realizou-se a análise de conteúdo (Bardin, 1977/1979), envolvendo:

a) Identificação dos temas e sua posterior divisão em unidades de respostas;

b) Recorte dos textos de acordo com os conteúdos apresentados;

c) Agrupamento e categorização das unidades de respostas, que representam o conjunto de ideias comuns ao grupo pesquisado.

\section{RESULTADOS E DISCUSSÃO}

Para além dos dados coletados por meio das entrevistas, foi possível observar junto aos professores a imprevisibilidade da escola, o acúmulo de tarefas dentro e fora da sala de aula e a dupla ou tripla jornada de trabalho. Assim, os horários agendados para as entrevistas, com no mínimo uma semana de antecedência, foram frequentemente tomados pela falta de outro professor e a demanda de substituição em sala de aula, pela necessidade de preenchimento de inúmeros documentos e formulários ou ainda por outros eventos imprevistos. Dessa forma, vivenciamos a dificuldade das professoras em exercerem o mínimo de autonomia, em dedicarem-se a atividades outras que não reproduzissem a crônica, conturbada e acelerada rotina da escola.

Pode-se dizer que a maior parte das entrevistadas participou do processo de transição dos paradigmas da educação especial, partindo da integração e atualmente vivenciando a busca por práticas que respondam aos pressupostos da educação inclusiva.

Observamos relatos de professores que ilustram este momento de transição da educação, quando falam da inserção gradual de alunos com deficiência que, com muitas restrições e concessões a apenas alguns diagnósticos, tinham acesso às salas especiais da escola regular, reproduzindo-se, portanto, a exclusão dentro dos muros escolares, com a constituição de espaços restritamente diferenciados aos "diferentes", conforme podemos observar na fala de uma professora:

Antes a inclusão era muito pouca, e você tinha mais alunos com deficiência auditiva; mentais eram poucos porque eles ficavam mais no $X$ [Escola de Educação Especial no Município] né, em outras instituições... Aí depois eu lembro que eles começaram a inserir aqueles que tinham Down, e autismo. Mas eles tinham acompanhamento separado dentro do mesmo período [sala especial], você tinha aquelas salas como você tem a S.A.N.E.E. [atual Sala de Recursos Multifuncionais] hoje, mas eles trabalhavam muito mais lá e menos com a gente. (Professora 1)
Esse panorama começa a ser transformado com a Lei de Diretrizes e Bases da Educação Nacional (Lei no 9.394, 1996), que preconiza que cabe aos sistemas de ensino assegurar aos estudantes currículo, métodos, recursos e organização específicos para atendimento de suas necessidades. A lei ultrapassa, assim, o limite da integração, pois adequa o sistema às necessidades do aluno, buscando transformar o contexto escolar e reduzindo suas restrições, que anteriormente eram compreendidas como sendo dos alunos. A escola passa a ser vista como discriminatória e efetiva-se, dessa forma, a busca por uma nova perspectiva de compreensão da deficiência, uma compreensão social, por meio da qual se possa superar o atendimento restrito aos padrões homogêneos de existência.

Trata-se, entretanto, do plano legislativo, que não se transfere imediatamente à complexidade do cotidiano escolar, conforme nos relatam as entrevistadas. Quando questionadas sobre a inclusão, aparecem, de imediato, desabafos, angústias e dificuldades, que falam de um processo que tem se imposto às práticas pedagógicas sem a participação dos professores no que diz respeito a formulações e decisões, pois afirmam participarem apenas da execução da lei, sem, entretanto, compreendê-la. Discordam em grande parte, concebendo muitas vezes o processo como falho ou ineficaz.

Conforme apontado por Ainscow (2000), aqueles que defendem a necessidade de reformas nos sistemas educacionais, que legislam e gerem novos paradigmas para a compreensão da educação, precisam se lembrar que as políticas de educação são, em última análise, aquilo que se passa por detrás da porta da sala de aula. Neste sentido,

... os professores são "fazedores" de política. A forma como eles decidem interpretar as orientações externas enquanto interagem com as suas turmas, constitui, de fato, a ação política relevante. Assim, para que as mudanças tenham lugar, é indispensável que sejam geridas de forma a assegurar a participação de um corpo docente empenhado e confiante. Consequentemente, deve ser dada toda a atenção aos modos como este processo de envolvimento pode ser promovido. (Ainscow, 2000, p. 2).

Dentre os relatos, emergem diversas concepções sobre um processo que tem se fundamentado na intuição, boa vontade ou ainda por meio de tentativas e erros dos professores que atuam com os alunos com deficiência; professores estes que lidam, dentro das salas de aula, com as falhas nos processos de formação e de apoio para a efetividade do processo de inclusão, que nem sempre se concretiza, conforme relata a professora 1 : "Tem muita coisa que eu não sei, que eu não me sinto capaz de estar trabalhando com eles, só boa vontade 
às vezes não dá. Não é suficiente". Ou ainda conforme ilustrado na fala da professora 7: "Até hoje a gente vai levando meio que na própria pesquisa, na intuição, no carinho, que a gente se apega com a criança".

Algumas professoras concebem inclusão como processo que precisa ser revisto, discordando da forma como tem ocorrido, mas acreditam ser um processo necessário. Entretanto, questionam-se se, na atual conjuntura, estariam beneficiando ou prejudicando os alunos, tendo em vista a ausência de parceria com o atendimento especializado para amparar e complementar o trabalho realizado em sala de aula, assim como precárias condições estruturais básicas, que vão desde a inadequação do espaço físico à escassez de recursos e métodos.

Nesse contexto, as professoras se sentem frequentemente sobrecarregadas e solitárias, sem condições de colocar em prática as diretrizes da educação inclusiva, colaborando para um processo que pode se transformar em seu avesso, em exclusão, ou ainda manifestando a ideia de que a criança deve se enquadrar em determinado perfil para ser incluída na escola, conforme demonstrado na fala a seguir:

Eu acho que a inclusão é válida desde que a criança tenha condições de ser incluída, porque eu acho que tem casos, tem síndromes que não tem condições de ficar numa sala com trinta ou trinta e cinco alunos, sem suporte, sem estrutura. Aí acaba não sendo inclusão, acaba sendo exclusão. A inclusão então é válida sim desde que a criança tenha condições de ser incluída. (Professora 3).

Aparece também, na fala das professoras, uma ideia de inclusão como ensino diferenciado voltado a crianças que não têm capacidade de acompanhar os demais alunos em sala de aula, demandando uma atenção individualizada, com adaptações metodológicas e curriculares, para que o aluno tenha oportunidades de desenvolvimento segundo suas habilidades, potencialidades e limitações, sendo algumas dessas falas associadas a uma concepção de educação inclusiva enquanto via de inserção social, necessária para o desenvolvimento pleno do aluno, como sujeito de direitos.

Consideramos que quando o professor busca, mesmo com todas as dificuldades e falhas do processo, construir junto ao aluno uma prática que vai ao encontro de suas necessidades e particularidades, está buscando a construção de um paradigma inclusivo, um salto adiante, rumo a objetivos que não visam padrões pré-estabelecidos de aluno ideal, mas atingir o máximo da sua potencialidade, junto com os seus colegas "normais", garantindo-se, assim, o direito à singularidade. No paradigma da inclusão não são os "deficientes" que tem de se adaptar aos "normais", mas os "normais" é que precisam aprender a conviver com a diferença.
Algumas professoras referem-se a uma prática pedagógica que parte do pressuposto apresentado na Declaração Universal dos Direitos Humanos (ONU, 1948), conjugando igualdade e diferença como valores indissociáveis, sendo a educação inclusiva apenas mais um passo em direção a esse pressuposto básico. Nessa perspectiva, uma das professoras concebe sua atuação junto a alunos com deficiência de acordo com suas necessidades, atendendo de maneira diferenciada os diferentes, segundo suas demandas. É possível aproximar tal concepção de um dos princípios básicos de acesso universal aos serviços de saúde pública no nosso país, o princípio da equidade, que preconiza o dever de atender igualmente o direito de cada um, respeitando suas diferenças.

Além das dificuldades abordadas acima, o grande número de alunos por sala de aula, que segundo relatos corresponde a cerca de trinta e cinco a trinta e oito alunos, prejudica sobremaneira o atendimento diferenciado, acentuando-se ainda mais quando a professora não pode contar com a presença de uma auxiliar, o que é apontado como problema por três professoras.

Apenas duas professoras, de duas unidades municipais de ensino distintas, relatam a questão do espaço físico como sendo, ainda hoje, um obstáculo ao processo de inclusão, referindo-se tanto ao espaço físico da escola quanto ao mobiliário padrão, que é inadequado para atender as necessidades especiais relativas às deficiências físicas de determinados alunos. Essas questões são evidenciadas no relato da professora 4: "se for um cadeirante, por exemplo, é complicado, porque a maior parte da escola tem acesso por escadas" - e da professora 2:

Eu trabalho com aluno cadeirante, por exemplo; banheiro deveria ser totalmente adaptado. A auxiliar tinha uma dificuldade extrema de estar levando a menina, não tem aquela adaptação do vaso pra ela. A escola tem de se preparar pra receber esse aluno já que ele vem pra cá. $O$ ano passado colocamos até livros embaixo da cadeira pra ver se subia um pouco mais a mesinha pra ela; o pai que estava correndo atrás, que está vendo se consegue adaptar uma mesinha mais alta pra ela. (Professora 2).

Apesar de inúmeros documentos garantirem a acessibilidade como direito, a fala da professora nos mostra claramente a dificuldade em se produzir um ambiente menos restritivo que atenda às necessidades individuais de cada aluno.

Nesse sentido, podemos resgatar a Política Nacional de Educação Especial na Perspectiva da Educação Inclusiva, que se refere ao tema quando cita, dentre seus objetivos para assegurar a inclusão, orientar os sistemas

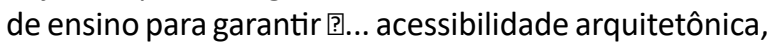


nos transportes, nos mobiliários, nas comunicações e informação? (Brasil, 2008, p.14).

Segundo relatado, esse processo de adaptações tem se dado paulatinamente, muito menos a partir da reorganização institucional para cumprir a legislação e muito mais a partir das situações específicas e de iniciativas locais, de modo que observamos, como no exemplo citado, uma mobilização de toda a comunidade escolar e seus agentes, alunos e familiares, para construção do processo de inclusão. Tal contexto nos remete mais uma vez a um processo educacional inclusivo que se reflete na sociedade como um todo, e se vê envolvido por ela, exemplificando o que nos mostra Michels (2006, p. 406) quando afirma: ? $\mathrm{a}$ escola assume potencialmente o papel de transformar a sociedade. Portanto, ela é produto e produtora das relações sociais?. Contudo, embora se reconheça a influência mútua entre escola e sociedade, o Estado, enquanto organizador das aspirações sociais, é visto como impositor de medidas pouco plausíveis nas precárias condições por ele mesmo proporcionadas.

Duas professoras questionam o papel da Secretaria de Educação e do MEC, enquanto órgãos gestores, no atendimento educacional especializado, pois segundo elas haveria a necessidade de apoio ou de acompanhamento do trabalho dos professores, de modo a oferecer suporte para as questões que vêm sendo discutidas, o que aparentemente não acontece, conforme relato da professora 6: ? ?Não vem ninguém dar um apoio para gente poder desenvolver um trabalho melhor?. Esse questionamento também é evidenciado na fala da professora 1:

Eles fazem as leis né, o MEC determina as coisas, difícil é colocar em prática. Eu acho que dá certo, desde que você tenha um suporte. Minha expectativa é essa, de que todo mundo faça sua parte, né. Porque não adianta você querer resultado só de um lado [do professor]. Não funciona. Não vai dar o resultado que deveria dar. (Professora 1).

Neste sentido, uma das professoras ressalta um desajuste entre o que é preconizado e o que é passível de se efetivar na prática cotidiana; em outras palavras, aponta a necessidade de aproximação entre estes órgãos e a realidade escolar vivenciada, de modo mais intenso, por professores e alunos.

Michels (2006) sublinha uma importante mudança no âmbito da gestão pública a partir das reformas neoliberais do Estado: o abandono de seu caráter intervencionista e provedor para constituir-se simplesmente em Estado regulador, de modo que no campo da educação, sob a égide de uma suposta democratização, implementa-se uma descentralização administrativa. Dessa forma, segundo o autor, o governo federal se isenta de responsabilidades, repassando-as principalmente aos municípios. Não obstante, observa-se que:

Nesta mesma lógica (sob o discurso da democratização), as unidades escolares acabam por assumir a responsabilidade pela ação educativa, convertendo-se, então, em foco privilegiado da gestão. É sobre a escola que incidem as exigências pela formação de uma nova ?mentalidade? política e social. (Michels, 2006, p. 421).

Dessa forma, a professora tem toda razão quando questiona a falta de atuação efetiva dos órgãos gestores e denuncia mais uma vez a sobrecarga dos professores que atuam de maneira precária, desinformada e muitas vezes solitária. Sendo assim, observamos a isenção do poder público que preconiza, mas não cria condições efetivas de execução, de modo que o professor aparece como elemento decisivo na concretização dessa versão de gestão pública, ou seja, assume o papel de mero executor da educação. Em última instância, o governo propõe - quando propõe - para os professores uma formação aligeirada e utilitarista, que pouco se preocupa com o bem-estar destes no processo inclusivo, mas exige dos mesmos que o processo aconteça, da melhor forma, conforme preconizado, ou seja, cabe ao professor "fazer dar certo".

Aparecem ainda questões referentes às dificuldades com adaptações do processo de avaliação de alunos com deficiência, pois, segundo uma das professoras, o que ela faz, em relação à evolução do aluno e de modo qualitativo, torna-se uma informação que permanece restrita à escola; entretanto, o que é levado em conta pela prefeitura são números, estatísticas, avaliações quantitativas, que não retratam o processo individual de desenvolvimento dos alunos.

Assim, conforme vimos discutindo, o Estado aparece como simples regulador, cobrando resultados. De acordo com Michels,

O Estado retrai-se na provisão, destacando o papel da unidade escolar como responsável pela educação das crianças, jovens e adultos, mas mantendo o controle do que é feito pela escola por meio da avaliação (SAEB - Sistema de Avaliação da Educação Básica, ENEM - Exame Nacional do Ensino Médio, ENC - Exame Nacional de Cursos [atual ENADE - Exame Nacional de Desempenho Escolar]). (Michels, 2006, p. 408).

\section{CONSIDERAÇÕES FINAIS}

É necessário ressaltar que esse trabalho não busca contemplar todos os questionamentos e desdobramentos que se relacionam à política de educação inclusiva. Seria ilusão pensar que tal tarefa poderia se concretizar. $O$ trabalho aqui apresentado é apenas um recorte de como esse processo tem ocorrido em três unidades 
municipais de ensino de um único município, de forma que ao estabelecermos contato com o que pensam e vivenciam alguns de seus professores, tivemos a oportunidade de refletir acerca das lacunas existentes entre o que é preconizado e a sua efetividade, assim como compreender como os ditames dessa política ecoam e repercutem dentro da escola e na prática dos professores.

Apesar de indicado e amplamente discutido no âmbito das legislações, observamos que o processo de educação inclusiva tem se dado de maneira intuitiva e que conta, ainda hoje, com a sensibilidade e dedicação dos professores, que muitas vezes caminham sozinhos na busca por melhores condições de inclusão dos alunos com deficiências.

Pudemos apreender da fala das professoras um processo de inclusão com o qual muitas vezes discordam, tendo em vista a maneira como tem ocorrido. Entretanto, a partir da visão de educação enquanto direito constitucional do aluno, buscam superar as dificuldades na medida do possível, por meio da intuição ou boa vontade, tentativas e erros, em favor de um processo que possibilite abertura para a sociedade, de forma que a inclusão nas atividades escolares seja apenas o primeiro passo, tanto para o desenvolvimento do aluno público alvo da política de educação inclusiva, como para a sociedade como um todo, que necessita de drásticas mudanças no sentido de compreensão das diferenças.

Nesse sentido, observamos que, conforme ressalta Michels (2006), as políticas educacionais não estão sozinhas na sociedade, mas se relacionam intrinsecamente com a realidade social mais ampla, de modo que as mudanças que ocorrem na sociedade buscam na educação um alicerce.

Precisamos compreender ainda que incluir pessoas com deficiências ou transtornos no atual contexto de precarização que se evidenciou nos persistentes relatos, não rompe por si só com o circuito da exclusão. Por isso, a proposta da educação inclusiva não pode ser pensada de maneira desarticulada da luta pela melhoria e transformação da educação como um todo.

Portanto, tendo em vista as diretrizes inclusivas em contraposição à realidade institucional, observou-se que é direito constitucional do aluno a matrícula na instituição regular de ensino, porém, inclusão não significa apenas matricular todos os educandos público alvo desta política nas salas regulares, mas significa também dar ao professor e à escola o suporte necessário à sua ação pedagógica priorizando práticas inclusivas e dialógicas.

Por fim, muitas das questões apresentadas dizem respeito a problemas existentes há várias décadas na estrutura educacional do país, que se referem à educação da totalidade dos alunos, e não apenas dos que apresentam algum tipo de deficiência ou transtorno, evi- denciando que a questão da inclusão não é, e não deve ser, vista sob a perspectiva da ordem pessoal, cabendo ao indivíduo superá-la, mas que profundas modificações devem ser realizadas a fim de melhorar a qualidade da educação em geral, superando os diferentes desafios que se apresentam no contexto escolar.

\section{REFERÊNCIAS}

Ainscow, M. (2000). O processo de desenvolvimento de práticas mais inclusivas em sala de aula. In British Education Research Association (Ed.), Simpósio "Improving the quality of education for all" Anais (pp. 1-16). Cardiff. Recuperado em 17 de agosto de 2020, de https://issuu.com/jbarbo00/ docs/inclusao1

Anjos, H. P. dos; Andrade, E. P. de; Pereira, M. R. (2009). A inclusão escolar do ponto de vista dos professores: o processo de constituição de um discurso. Revista Brasileira de Educação, 40(14), 116-129.

Anjos, H. P. dos (2015). Pesquisa-formação e história de vida: entretecendo possibilidades em educação inclusiva. Revista Brasileira de Educação, 62(20), 619-633.

Bardin, L. (1979). Análise de conteúdo. São Paulo: Edições 70/Livraria Martins Fontes. Trabalho original publicado em 1977.

Brasil (2005). Educação inclusiva: direito à diversidade. Programa de educação inclusiva. Brasília: MEC. Recuperado em 03 de fevereiro de 2018, de http://portal.mec.gov.br/ seesp/arquivos/pdf/orientador1.pdf.

Brasil (2008). Política Nacional de Educação Especial na Perspectiva da Educação Inclusiva. Brasília: MEC. Recuperado em 03 de fevereiro de 2018, de http:// peei.mec.gov.br/arquivos/politica_nacional_educacao_ especial.pdf.

Figueiredo, R. V. (2002). Políticas de inclusão: escola gestão da aprendizagem na diversidade. In Rosa, D. E. G; Souza, V. C. de. (Eds.), Políticas organizativas e curriculares, educação inclusiva e formação de professores. (pp. 67-78). Rio de Janeiro: DP\&A.

Jesus, D. M. de. (2004). Atuando em contexto: o processo de avaliação numa perspectiva inclusiva. Psicologia \& Sociedade, 1(16), 37-49.

Lei no 9.394, de 20 de dezembro de 1996. (1996, de 20 de dezembro de 1996). Lei de Diretrizes e Bases da Educação Nacional. Brasília, DF: Diário Oficial da União. Recuperado de http://www.planalto.gov.br/CCIVIL_03/leis/L9394.htm.

Matos, S. N.; Mendes, E. G. (2015). Demandas de professores decorrentes da inclusão escolar. Revista Brasileira de Educação Especial, 1(21), 9-22.

Michels, M. H. (2006). Gestão, formação docente e inclusão: eixos da reforma educacional brasileira que atribuem contornos à organização escolar. Revista Brasileira de Educação, 33(11), 406-423.

ONU. (1948). Declaração Universal dos Direitos Humanos. Recuperado em 03 de fevereiro de 2018, de http://www. onu.org.br/img/2014/09/DUDH.pdf. 
Pletsh, M. D (2009). A formação de professores para a educação inclusiva: legislação, diretrizes políticas e resultados de pesquisas. Educar em Revista, 33, 143-156.

Sant'Ana, I. M. (2005). Educação inclusiva: concepções de professores e diretores. Psicologia em Estudo, 2 (10), 227-234.

UNESCO. (1990). Declaração Mundial de Educação para todos: satisfação das necessidades básicas de
Aprendizagem. Jomtien, Tailândia. Recuperado em 03 de fevereiro de 2018, de http://unesdoc.unesco.org/ images/0008/000862/086291por.pdf

UNESCO. (1994) Declaração de Salamanca: Sobre princípios, políticas e práticas na área das necessidades especiais. Salamanca, Espanha. Recuperado em 03 de fevereiro de 2018, de http://portal.mec.gov.br/seesp/arquivos/pdf/ salamanca.pdf.

Recebido: 28 de novembro de 2018

Aprovado: 06 de agosto de 2019 